Received: 28 April 2020 :: Accepted: 29 April 2020 :: Published: 30 April 2020

\title{
HUBUNGAN PENGGUNAAN ALAT PELINDUNG DIRI (APD) DENGAN KEJADIAN INFEKSI SALURAN PERNAPASAN AKUT (ISPA) PADA PEKERJA KILANG PADI
}

\author{
Reni Aprinawaty Sirait ${ }^{1}$, Vina Novianti ${ }^{2}$, luci ginting \\ Institut Kesehatan MEDISTRA Lubuk Pakam \\ Jl. Sudirman No. 38 Lubuk Pakam Kab . Deli Serdang (20512) \\ Email: renisirait82@yahoo.com \\ DOI : https://doi.org/10.35451/jkg.v2i2.417
}

\begin{abstract}
Respiratory Protection Equipment (APD) is a set of tools used by workers to protect all or part of their body from the possibility of potential occupational hazards such as ISPA (Upper Respiratory Infection) in Rice Refinery Workers in Dalu X-B Village, Tanjung Morawa Sub-District, Deli Serdang Regency. The number of patients with ARI in 2015 was found to be 452 cases and increased in 2016 by 469 cases. The use of respiratory protective equipment is often considered unimportant or trivial by workers, especially in workers who work in the informal sector. Every worker needs to wear respiratory protective equipment especially workers whose work environment contains a lot of dust so workers must be obliged to use a complete respiratory protective device when doing work because to maintain personal safety and personal health while working. This research was used analytic survey method by using cross sectional design. Samples were taken as many as 62 workers with sampling techniques using total sampling. This research was carried out in two rice milling industries in the village of Dalu X Village, Tanjung Morawa Sub-District, Deli Serdang Regency. The data collection was carried out by direct interview using a questionnaire to find out the data of the age of the workers, long work, and education level. Data analysis performed was univariate and bivariate with statistical tests using the Chi Square test with $a=0.05$. With the results there was a relationship between the use of respiratory protective equipment with the incidence of acute respiratory infections (ISPA) in Rice Refinery Workewith pValue $(=0.01) \leq a(=0.05)$. For rice refinery workers must be able to comply with regulations that have been determined in the use of masks and Rice refinery workers.
\end{abstract}

Keywords : Use of Respiratory Protective Equipment, Respiratory.

\section{PENDAhUlUAN}

Dalam perkembangan tehnologi di era globalisasi saat ini Indonesia ditantang untuk mengikuti perdagangan bebas sehingga jumlah tenaga kerja yang disektor industri akan bertambah dengan pesat seiring dengan pertambahan jumlah industri (Kustianto. A, 2012). Masalah industri yang terjadi berkiprah pada masalah Keselamatan dan Kesehatan Kerja (K3). Diantaranya industri penggilingan padi yang bergerak dibidang pemenuhan swasembada pangan. Bahaya Penyakit akibat kerja seperti penyakit pneumocoinosis, yaitu penyakit infeksi saluran pernapasan yang disebabkan oleh debu atau 
partikel yang masuk dan mengendap di dalam paru-paru (Marlani, 2014). Hal ini terjadi karena paparan debu padi pada proses penggilingan padi yang terpapar pada pekerja secara kontinu. (Depkes RI, 2012). Proses penggilingan dimulai dengan penjemuran, penggilingan, sampai dengan proses pengemasan untuk di produksi. Penyakit infeksi saluran pernafasan dan penyakit gangguan fungsi paru dapat terjadi pada pekerja yang diakibatkan paparan debu pada proses penggilingan padi, hal ini merupakan salah satu masalah yang di hadapi oleh pekerja khusunya bidang produksi beras di Indonesia (Beeklake, 2010).

Para tenaga kerja yang bekerja di penggilingan padi memiliki potensi yang lebih besar dibandingkan pada pekerja lainnya, terpapar debu yang terdapat pada proses penggilingan padi, pecahan kulit gabah menghasilkan debu sekam padi/Dust Grain Worker. Debu sekam padi berpotensi menimbulkan gangguan pernapasan pada tenaga kerja lainnya yang bertugas di dalam ruangan penggiliangan padi tersebut (Kusuma, 2013).

Salah satu peningkatan teknologi pada bidang pertanian adalah penggunaan mesin traktor, mesin perontok padi dan mesin penggilingan padi. Pencemaran udara berupa partikel debu dapat terjadi akibat petugas kerja tidak memakai alat pelindung pernafasan saat menggunakan mesin penggilingan padi (Mengkidi, 2010). Hal ini merupakan potensi bahaya lingkungan kerja di bidang pertanian, sehingga secara langsung maupun tidak langsung mengancam kesehatan tenaga kerja. Kondisi ini merupakan salahsatu penyebab penyakit infeksi saluran pernafasan dan juga ganguan pendengaran pada pekerja, yang timbul karena kurangnya kepatuhan terhadap Alat Pelindung Pernapasan seperti tidak memakai masker pada saat bekerja (Halim. D, 2014).

Banyaknya kerugian yang ditimbulkan dari ketidakpatuhan tenaga kerja terhadap penggunaan Alat Pelindung pernafasan membuat perusahaan harus memberikan sanksi tegas terhadap pekerja yang tidak menggunakan alat pelindung pernafasan Penyakit ISPA merupakan Penyakit Akibat Kerja yang banyak terjadi pada tenaga kerja yang disebabkan kurangnya penggunaan Alat Pelindung Pernapasan (Humau, Dina C. 2012). Penggunaan alat pelindung pernafasan seperti masker untuk mengurangi resiko paparan debu di wilayah kerja industri seperti pabrik pengilingan padi. Di Malaysia, kamboja, Thailand pada tahun 2014 diperkirakan lebih dari 150.000 tenaga kerja di penggilingan padi mengalami penyakit ISPA (sutrisno, 2014).

Berdasarkan data dari kementerian kesehatan tahun 2012, bahwa jumlah pekerja di Indonesia yang mengalami trend peningkatan gangguan fungsi pernafasan yaitu sebanyak 7.281.411 kasus dan 765.333 kasus pneumonia pada tahun 2011 selanjutnya pada tahun 2012 jumlah kasus ISPA berkategori batuk bukan pneumonia sebanyak 18.790.481 kasus dan 756.577 kasus pneumonia. Hal ini di dukung dengan laporan HIPERKES dan Keselamatan kerja bahwa hasil pemeriksaan kapasitas paru terhadap 90 tenaga kerja di penggilingan padi tenaga kerja di penggilingan padi mengalami penyakit ISPA. (sutrisno, 2014).

Data dari Riskesdas tahun 2013, menunjukkan prevalensi ISPA pada pekerja penggilingan padi mencapai sebanyak 45,0\%, hal ini disebabkan beberapa faktor diantaranya tidak 
menggunkan salah satunya tidak menggunakan alat pelindung pernafasan sehingga pekerja padi terus menerus kontak langsung dengan paparan debu di lingkungan kerja (Taty, 2012).

Berdasarkan data profil kesehatan provinsi sumatera utara pada tahun 2015 terdapat 337 kasus yang mengalami gangguan pernapasan yang dialami oleh pekerja penggilingan padi di sumatera utara. Selanjutnya tahun 2016 terdapat 148.431 kasus yang menderita ISPA pada pekerja. Kabupaten dengan jumlah penderita kasus ditemukan dan ditangani terbanyak adalah kabupaten simalungun yaitu $53 \%$,disusul dengan kota medan sebesar $31 \%$ dan kabupaten Deli Serdang sebesar $16 \%$. Pada tahun 2015 sebesar 153.921 kasus ditemukan. kabupaten dengan jumlah penderita kasus ditemukan dan ditagani terbanyak adalah kabupaten karo sebesar 44,1\%,disusul dengan kabupaten tapanuli utara sebesar $31,2 \%$ dan kabupaten nias selatan sebesar 24,7 \%. Bedasarkan data kasus ISPA dari tahun ke tahun, dapat diketahui bahwa terjadi peningkatan. Peningkatan ini menunjukan bahwa penyakit ISPA masih belum teratasi dan merupakan kasus yang perlu mendapat perhatian khusus (Profil Dinas Kesehatan Provinsi Sumatera Utara 2016). Tahun 2015 jumlah Penderita ISPA di Kabupaten Deli Serdang sebanyak 211.511 kasus yang ditemukan (Dinkes Kabupaten Deli Serdang, 2015).

Data yang diperoleh peneliti dari Puskesmas Dalu X-B bahwa pada bulan Januari-Desember 2015 jumlah penderita penyakit ISPA tercatat 452 Kasus dan pada bulan Januari-Oktober 2016 tercatat 469 Kasus. Dari hasil survai pendahuluan yang telah dilakukan 62 tenaga kerja di industry penggilingan padi di desa dalu X-B terdapat 40 pekerja kilang padi mengalami keluhan kesehatan berupa sesak napas, sakit dada, dan batuk. Pekerja mengalami keluhan tersebut sebagian besar bekerja pada proses penggilingan dan penjemuran. para tenaga kerja yang bekerja 8 jam/hari (07.00-16.00 WIB) dan istirahat pada pukul 12.00-01.00 WIB) tersebut mayoritas menghirup debu dari biji padi hasil penggilingan dan penjemuran, selain itu mereka juga menghirup debu-debu yang berasal dari lingkungan. Pada kenyataanya pekerja tidak menggunakan alat pelindung pernafasan seperti masker dan sebagian besar pekerja masih belum menyadari pentingnya penggunaan masker. Berdasarkan latar belakang di atas maka perlu dilakukan penelitian tentang hubungan penggunaan alat pelindung diri (APD) dengan kejadian infeksi saluran pernapasan akut (ISPA) pada pekerja kilang padi Di Desa XB Kecamatan Tanjung Morawa Kabupaten Deli Serdang.

\section{METODE PENELITIAN}

Jenis penelitian ini yaitu dengan menggunakan observasional analitik dengan rancangan cross sectional study (Notoadmodjo, 2012). Penelitian ini dilaksanakan di Industri penggilingan padi di Desa Dalu XB Kecamatan Tanjung Morawa Kabupaten Deli Serdang.

Populasi penelitian ini adalah seluruh pekerja bagian proses pada dua penggilingan padi tersebut yaitu sebanyak 62 orang. Penarikan sampel menggunakan metode Total sampling. Pengumpulan data ini dilakukan dengan wawancara langsung menggunakan kuesioner untuk mengetahui data umur pekerja, lama bekerja, dan tingkat pendidikan. Analisis data yang dilakukan adalah univariat dan bivariat 
dengan uji Chi-Square (Sudigdo. S, 2011).

\section{HASIL PENELITIAN}

Berdasarkan tabel 1, diketahui bahwa responden terbanyak kategori umur $\geq 41$ tahun yaitu 30 orang responden $(48,1 \%)$ dan paling sedikit umur $\leq 20$ tahun yaitu 4 orang $(6,5 \%)$.

Tabel 1. Distribusi Responden Berdasarkan Karakteristik Umur

\begin{tabular}{|c|c|c|c|c|}
\hline $\begin{array}{l}\mathrm{N} \\
\mathrm{O}\end{array}$ & $\begin{array}{l}\text { Karak } \\
\text { teristik }\end{array}$ & Kategori & $\begin{array}{l}\text { Freku } \\
\text { ensi }\end{array}$ & $\%$ \\
\hline \multirow[t]{3}{*}{1} & Umur & $\begin{array}{l}\leq 20 \text { tahun } \\
21-40 \\
\text { tahun }\end{array}$ & $\begin{array}{l}4 \\
28\end{array}$ & $\begin{array}{l}6,5 \\
45, \\
2\end{array}$ \\
\hline & & $\geq 41$ tahun & 30 & $\begin{array}{l}48, \\
1\end{array}$ \\
\hline & & Total & 62 & 100 \\
\hline
\end{tabular}

Tabel 2. Distribusi Responden

Berdasarkan Karakteristik Tingkat Pendidikan

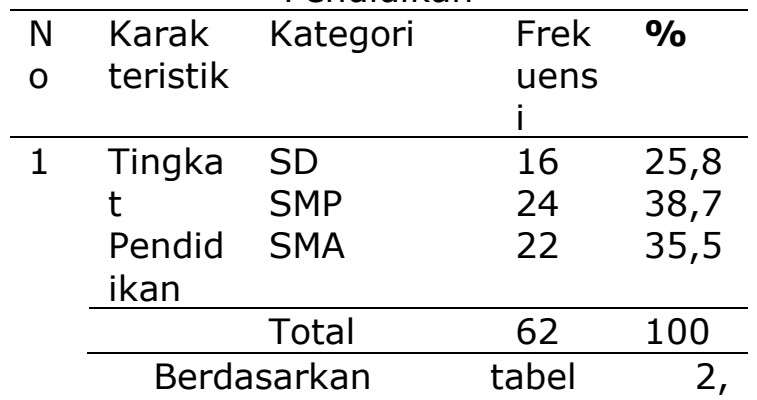

menunjukkan bahwa paling banyak responden tingkat Pendidikan SMP yaitu 24 orang $(38,7 \%)$ dan paling sedikit SD yaitu 16 orang $(25,8 \%)$.

Tabel 3. Distribusi Responden Berdasarkan Karakteristik Lama Bekerja

\begin{tabular}{|c|c|c|c|c|}
\hline $\begin{array}{l}\mathrm{N} \\
\mathrm{O}\end{array}$ & $\begin{array}{l}\text { Karak } \\
\text { teristik }\end{array}$ & Kategori & $\begin{array}{l}\text { Frek } \\
\text { uens } \\
\mathrm{i}\end{array}$ & $\%$ \\
\hline \multirow[t]{3}{*}{1} & Lama & $\geq 5$ tahun & 41 & 66,1 \\
\hline & $\begin{array}{l}\text { Bekerj } \\
\text { a }\end{array}$ & $\leq 5$ tahun & 21 & 33,9 \\
\hline & & Total & 62 & 100 \\
\hline
\end{tabular}
bahwa lama bekerja responden paling banyak $\geq 5$ tahun yaitu 41 orang $(66,1 \%)$ dan paling sedikit $\leq 5$ tahun yaitu 21 orang

( $33,9 \%)$.

Berdasarkan tabel 4, bahwa pekerja yang menggunakan alat pelindung diri pada pekerja kilang padi sebanyak 8 orang $(12 \%)$ dan yang tidak menggunakan alat pelindung diri sebanyak 54 orang (88).

Tabel 4. Distribusi Responden Berdasarkan Penggunaan Alat

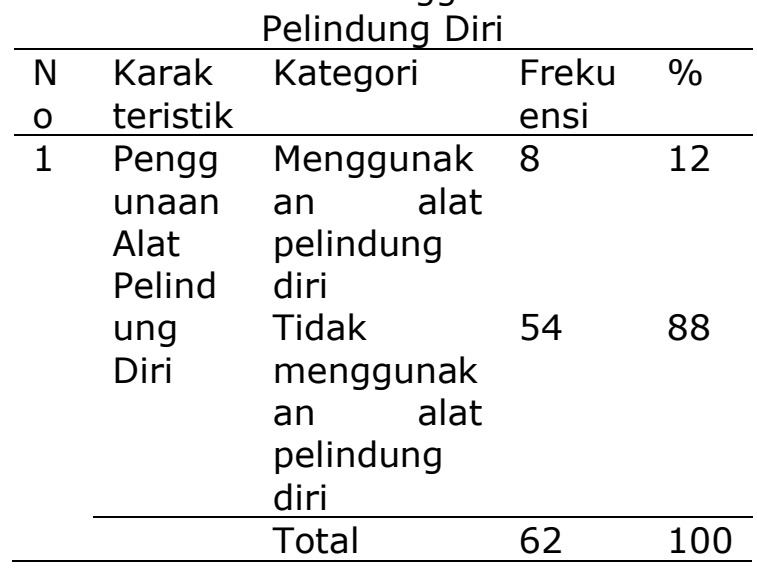

Tabel 5. Distribusi Responden Berdasarkan Kejadian ISPA

\begin{tabular}{lllll}
\hline $\mathrm{N}$ & $\begin{array}{l}\text { Karak } \\
\text { teristik }\end{array}$ & Kategori & $\begin{array}{l}\text { Freku } \\
\text { ensi }\end{array}$ & $\%$ \\
\hline 1 & $\begin{array}{l}\text { Kejadi } \\
\text { an }\end{array}$ & $\begin{array}{l}\text { Pernah } \\
\text { kejadian }\end{array}$ & 25 & 40,3 \\
& ISPA & $\begin{array}{l}\text { ISPA } \\
\text { Tidak }\end{array}$ & 37 & 59,7 \\
& $\begin{array}{l}\text { pernah } \\
\text { kejadian }\end{array}$ & & \\
& & & \\
& ISPA & & \\
& Total & 62 & 100 \\
\hline
\end{tabular}

Berdasarkan tabel 5, bahwa pekerja dengan kejadian ISPA sebanyak 25 orang $(40,3 \%)$ dan yang tidak pernah kejadian ISPA sebanyak 37 orang $(59,7 \%)$.

Berdasarkan tabel 6, dapat diketahui dari 62 pekerja kilang padi yang menggunakan alat pelindung diri sebanyak 8 orang (100.0\%) yang tidak pernah terjadi ISPA sebanyak 0 orang $(0.0 \%)$. Sedangkan yang tidak mengunakan Alat Pelindung diri 
sebanyak 29 orang (41.5\%) yang Pernah terjadi ISPA sebanyak 25 orang (46.3\%). Berdasarkan hasil analisis uji statistik menunjukkan bahwa variabel penggunaan alat pelindung diri pada pekerja kilang padi dengan kejadian ISPA dengan nilai $p(0,01)<a(0,05)$. Artinya ada Hubungan Alat Pelindung diri Dengan Kejadian Infeksi Saluran Pernapasan Akut (ISPA) Pada Pekerja Kilang Padi.

Tabel 6

Hubungan Penggunaan Alat Pelindung Diri dengan kejadian ISPA Pada Pekerja Kilang Padi

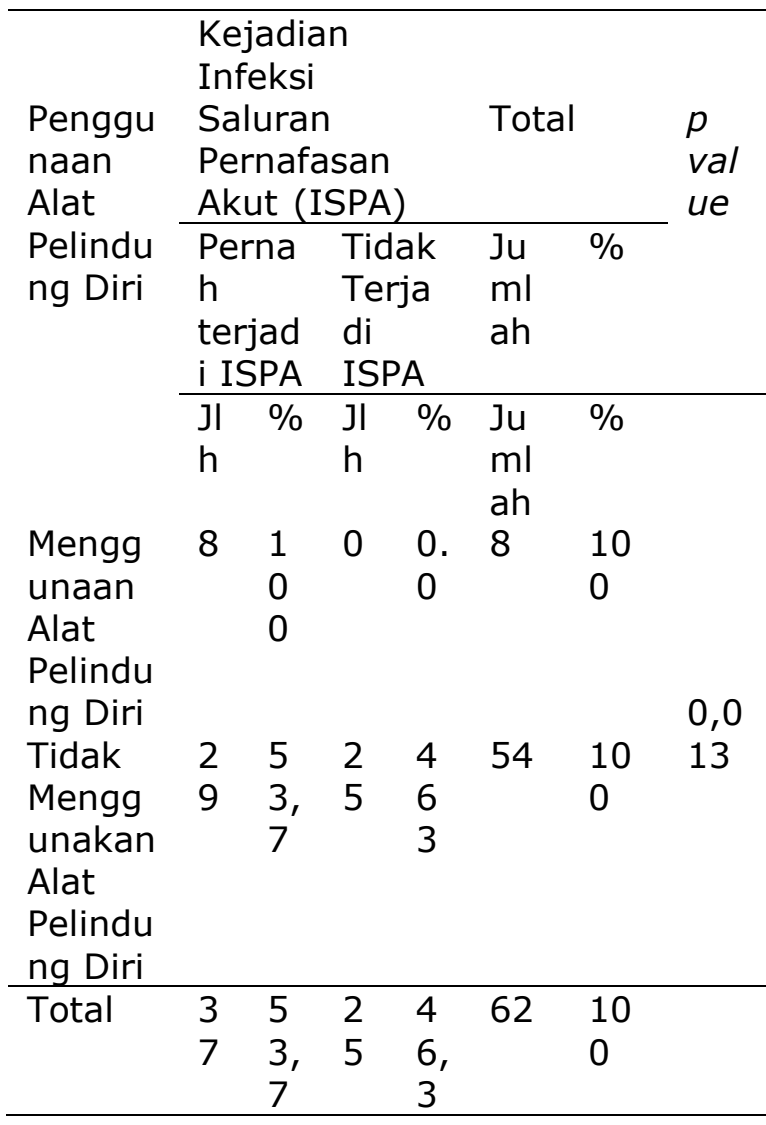

\section{PEMBAHASAN}

Hasil analisis uji Chi-square pada tingkat kepercayaan $95 \%$ dan alpha 0,05 diperoleh nilai $\rho$ value 0,01 artinya ada hubungan yang bermakna antara Pengunaan Alat Pelindung diri dengan Kejadian ISPA. Hal ini disebabkan pekerja di kilang padi merasa tidak nyaman dalam menggunakan alat pelindung diri sehingga debu yang berasal dari sekam padi tersebut lebih banyak mereka hirup hal tersebut membuat pekerja kilang padi mengalami Infeksi Saluran Pernapasan Akut (ISPA).

Sejalan dengan penelitian yang telah dilakukan oleh Roky Markino tahun 2010, yang menyebutkan ada hubungan penggunaan alat pelindung diri dengan kejadian penyakit infeksi saluran pernapasan akut (ISPA) pada pekerja kilang padi di desa Dalu $x-b$ kecamatan tanjung morawa kabupaten Deli Serdang tahun 2017.

Suatu kegiatan industri, paparan dan risiko yang ada ditempat kerja tidak selalu dapat dihindari. Upaya untuk pencegahan terhadap kemungkinan penyakit akibat kerja dan kecelakaan kerja harus senantiasa dilakukan. Ada beberapa alternative pengendalian (secara teknik dan administratif) yang bisa dilaksanakan, Namun mempunyai beberapa kendala. Pilihan yang sering dilakukan adalah melengkapi tenaga kerja dengan Alat Pelindung diri dijadikan suatu kebiasaan dan keharusan. Hal ini sesuai dengan Undang- Undang No 1 tahun 1970 tentang Keselamatan Kerja khusunya pasal 9, 12, dan 14 yang mengatur penyediaan dan penggunaan alat pelindung diri di tempat kerja baik pengusaha maupun tenaga kerja (Suma'mur, 2012).

Alat pelindung diri diri adalah alat pelindung untuk pekerja agar aman dari bahaya atau kecelakaan akibat melakukan suatu pekerjaannya (Siswanto, 2013). Alat pelindung pernapasan untuk pekerja di Indonesia sangat banyak sekali permasalahaanya dan masih dirasakan banyak kekurangannya Alat pelindung pernapasan yang baik adalah pelindung pernapasan yang memenuhi standar kemanan dan kenyamanan bagi pekerja 
(Safety and acceptation), apabila pekerja memakai alat pelindung pernapasan merasa kurang nyaman dan penggunaanya kurang bermanfaat bagi pekerja maka pekerja enggan memakai walaupun memakai karena terpaksa atau hanya berpura-pura sebagai syarat agar masih diperbolehkan untuk bekerja atau menghindari sanksi perusahaan (Budiono, 2013).

\section{KESIMPULAN}

1. Umur responden Pada pekerja Kilang padi paling banyak $\geq 41$ tahun sebanyak 30 orang $(48,1 \%)$, berdasarkan Pendidikan paling banyak SMP yaitu 24 orang $(38,7 \%)$ dan berdasarkan lama bekerja responden paling banyak $\geq$ 5 tahun yaitu 41 orang $(66,1 \%)$

2. Responden tidak menggunaan alat pelindung pernafasan sebanyak 54 orang $(88 \%)$ dan menggunakan alat pelindung pernafasan 8 orang $(12 \%)$ dan terjadi ISPA dengan tidak menggunakan alat pelindung diri sebanyak 29 orang $(53,7 \%)$.

3. Ada hubungan penggunan alat pelindung diri dengan kejadian Infeksi saluran pernapasan akut (ISPA) pada pekerja kilang padi di Desa Dalu X-B Kecamatan Tanjung Morawa Kabupaten Deli Serdang Tahun 2017

\section{DAFTAR PUSTAKA}

Allidawati, Kustianto. (2012). Teknologi Pemanfaatan Sekam Mendukung Program Agroindustri Padi. Laporan Akhir Penelitian Pengembangan Model Agroindustri Padi Berdaya Saing.

Beeklake. (2010). Faktor-Faktor yang berhubungan dengan Penggunaan Masker pada Pekerja Bagian Produksi Penggilingan Padi Wonogiri. Semarang: Fakultas Ilmu Kesehatan Masyarakat.

Budiono. (2013). Faktor yang Behubungan dengan Kepatuhan Penggunaan Alat Pelindung Diri APD pada Pekerja Bagian Ring
Frame PT. Lotus Indah Textile Industries di Surabaya. Skripsi;

Surabaya: FKM Universitas Airlangga.

Depkes RI. (2012). Pedoman Advokasi Program Keselamatan dan Kesehatan Kerja.

http://repository.usu.ac.id

Diakses 19 Januari 2016.

Humau, Dina C. (2012). Beberapa Faktor yang Berhubungan dengan Kepatuhan Penggunaan Alat Pelindung Diri APD pada Pekerja Bagian Ring Frame PT. Lotus Indah Textile Industries di Surabaya. Surabaya Skripsi FKM Universitas Airlangga

Halim, D. (2014). Infeksi Saluran Pernafasan Akut (ISPA) Dan Penganggulangannya, http://repository.usu.ac.id Diakses 19 Januari 2016.

Kusuma. (2013). Hubungan antara Kadar Debu Organik dan Risiko Gangguan Fungsi Paru Pada Pekerja Industri Penggilingan Padi di Kecamatan Margorejo, Kabupaten Pati Semarang. Program Keselamatan dan Kesehatan Kerja FKM Universitas Diponegoro.

Marlani. (2014). Deteksi Dini Penyakit Akibat Kerja,alih Bahasa dr Joko Suyono,Jakarta:EGC.

Mengkidi. (2010). Pengaruh Pajanan Debu Urea Terhadap Infeksi Saluran Pernafasab Akut (ISPA) Pada Pekerja Di Unit Pengantongan Pupuk Urea (PPU) PT. Pupuk Sriwijaya Palembang. Skripsi. Fakultas Kesehatan Masyarakat. Universitas Sriwijaya Palembang.

Notoadmodjo. (2012). Metodologi Penelitian Kesehatan. Rineka Cipta. Jakarta

Profil Dinas Kesehatan Provinsi Sumatera Utara. (2016). Rencana Pembangunan Jangka Menengah Daerah (RPJMD).

Profil Dinas Kesehatan Kabupaten Deli Serdang. (2015). Pedoman Advokasi Pencegahan Penyakit Menular dan tidak menular.

Roky Markino. (2010). Hubungan Masa Kerja dan Penggunaan APD 
Received: 28 April 2020 :: Accepted: 29 April 2020 :: Published: 30 April 2020

dengan Kapasitas Fungsi Paru

Pada Pekerja Kilang Padi

Kabupaten Banggai Provinsi

Sulawesi Tengah. Skripsi.

Fakultas Kesehatan Masyarakat.

Universitas Indonesia. Depok.

Sastroasmoro, Sudigdo. (2011).

Metode Penelitian Klinis. Sagung

Seto, Jakarta Sylvia, 2013.

Anatomi Fisiologi Untuk

Keperawatan. Jakarta: Rineka

Cipta.

Siswanto. (2013). Keselamatan dan Kesehatan Kerja, Manajemen dan Implementasi Kesehatan dan Keselamatan Kerja di Tempat Kerja. Surakarta: Harapan Press.

Suma'mur. (2012). Higiene Perusahaan dan Kesehatan Suma'mur. (2012). Higiene Perusahaan dan Kesehatan Kerja (Hiperkes). Jakarta: Seagung Seto.

Sutrisno. (2014). Jurnal Engenering Pertanian. Vol.III.No.:2. Balai Besar Pengembangan Mekanisme Pertanian.

Taty. (2012). Hubungan antara Karakteristik Pekerja dan Pemakaian Alat Pelindung Pernafasan dengan Kapasitas Fungsi Paru padaTenaga Kerja Di Penggilingan Padi Anggraini, Sragen Jawa Tengah . Jurnal Kesehatan Masyarakat. 